\title{
Correction to: Laparoscopic Anatomical Portal Territory Hepatectomy with Cirrhosis by Takasaki's Approach and Indocyanine Green Fluorescence Navigation (with Video)
}

Junhao Zheng, MD, Xu Feng, MD, PhD, Jingwei Cai, MD, Liye Tao, MD, and Xiao Liang, MD, PhD (1)

Department of General Surgery, School of Medicine, Sir Run Run Shaw Hospital, Zhejiang University, Hangzhou, Zhejiang, China

\section{CORRECTION TO: ANN SURG ONCOL} HTTPS://DOI.ORG/10.1245/S10434-020-08592-6

In the original version of the article all of the authors' first and last names were transposed. The original article has been updated.
Publisher's Note Springer Nature remains neutral with regard to jurisdictional claims in published maps and institutional affiliations.

The original article can be found online at https://doi.org/10.1245/ s10434-020-08592-6.

(C) Society of Surgical Oncology 2020

Published Online: 26 May 2020

X. Liang, MD, PhD

e-mail: srrshlx@zju.edu.cn 